\title{
A VARIAÇÃO QUE X QUEM EM DUAS CONSTRUÇÕES DE CLIVAGEM
}

\section{THE VARIATION OF THAT $x$ WHO IN TWO TYPES OF CLEFT CONSTRUCTIONS}

\author{
Carlos Felipe Pinto \\ Universidade Federal da Bahia \\ Salvador, Bahia, Brasil
}

RESUMO: Este artigo discute duas construções de clivagem no português para mostrar que, nessas construções não há uma oração relativa envolvida e que, em ambos os casos, a estrutura é a mesma, contendo uma oração completiva.

PALAVRAS-CHAVE: Gramática gerativa; Focalização; Clivagem; Cartografia.

ABSTRACT: This paper discusses two cleft constructions in Portuguese to show that in these constructions there is no relative clause involved and that in both cases the structure is the same, containing a thatclause.

KEYWORDS: Generative grammar; Focalization; Cleft constructions; Cartography 


\section{INTRODUÇÃO ${ }^{1}$}

Pensando na tipologia das construções de clivagem ${ }^{2}$, o português brasileiro (PB) é uma das línguas que apresenta mais quantidade de tipos. Chamam a atenção, entretanto, dois tipos (grifos meus):

a. Foram os alunos do primeiro ano que chegaram.

b. Foi ali que eu nasci.

c. Foi o livro de inglês que o Pedro comprou

d. Foi ontem que você foi lá.

(2) a. Foram os alunos do primeiro ano quem chegaram.

b. Foi ali onde eu nasci.

c. Foi o livro de inglês o que eu comprei.

d. Foi ontem quando você foi lá.

A diferença descritiva básica entre os dois tipos de construção é que, nos casos de (1), há um elemento "que" invariável independentemente da função sintática do foco e, no caso de (2), o marcador focal varia a depender da função sintática do foco.

A tradição anglo-saxônica analisa os dois tipos de construção como sendo do mesmo tipo, as chamadas it-clefts, independentemente de haver um elemento do tipo "that" ("que") ou "who" ("quem"). No caso do português, há uma variedade de análises, sendo a mais consensual na atualidade tratar (1) como clivada (CL) e (2) como pseudo-clivada extraposta (PCE).

Meu objetivo é apresentar uma análise em que ambos os tipos de construções de clivagem são derivadas através da mesma estrutura. Na seção 1 , apresento a definição da clivagem que assumo; na seção 2, apresento o problema teórico; na seção 3, comento algumas análises feitas para ambas as sentenças no português; na seção 4, argumento que as clivadas não são constituídas por orações relativas; na seção 5 , finalmente, proponho uma análise unificada para a CL e a PCE tentando explicar a variação entre as duas construções. Nas considerações finais, teço problemas residuais das questões levantadas neste trabalho que deverão ser debatidas em trabalhos futuros.

\footnotetext{
${ }^{1}$ A questão apresentada aqui foi inicialmente apresentada em Pinto (2008). Aqui, retomamos a questão com novos desdobramentos e novos argumentos, propondo uma análise mais consistente.

${ }^{2}$ É comum dividir as construções de clivagem em dois grupos: pseudo-clivadas e clivadas. As pseudo-clivadas são constituídas por uma oração relativa enquanto que as clivadas parecer ser de outro tipo. A tendência mais recente, como mostrarei ao longo do texto, é considerar as clivadas como um tipo de oração completiva.
} 


\section{A DEFINIÇÃO DE CLIVAGEM}

A definição de clivagem que norteia este trabalho é semelhante à apresentada por Modesto (2001, p. 21), baseada tanto em critérios sintáticos como semânticos: "As construções clivadas são orações especificacionais em que um movimento A-barra dispara leituras características de contraste, exclusividade e exaustividade". No entanto, minha análise difere da análise de Modesto (2001) porque ele analisa como clivagem orações que não apresentam uma estrutura típica, como "a conta pago eu", embora sejam também construções focais ${ }^{3}$.

Uma oração como em (3) pode ter duas leituras possíveis:

\section{O que este aluno é é desagradável.}

$\mathrm{Na}$ leitura especificacional, o aluno é desagradável, ou seja, ser desagradável é uma propriedade do aluno, diferentemente da leitura predicacional, em que não é o aluno que é desagradável, mas a propriedade do aluno, por exemplo, ser falador, que é desagradável ${ }^{4}$. Por isso, somente as orações com leitura especificacional podem ser consideradas construções de clivagem, porque somente nesse tipo de oração o valor da variável, que equivale ao elemento WH da relativa livre, pode ser fixado como no exemplo em (4) a seguir e o valor da oração expandida é o mesmo da oração contraída:

a. O que este aluno é é desagradável.

b. Existe um $x$, tal que este aluno é $x$.

c. $x=$ desagradável. $^{5}$

Ainda com relação à leitura semântica, Di Tullio (1999) discute, no espanhol, a diferença entre as orações equivalentes a (5) e (6), que linearmente apresentam a mesma ordem de constituintes ${ }^{6}$ :

\footnotetext{
${ }^{3}$ Moreno Cabrera (1999) trata a clivagem como "construções perifrásticas". O autor discute detalhadamente essa questão e mostra que a oração "contraída" deve conter o mesmo valor de verdade da oração "expandida" como ilustro nos exemplos a seguir:

(I) João chegou.

(II) Quem chegou foi João.

As orações em (I) e (II) devem ter o mesmo valor de verdade, ou seja, o mesmo significado. Partindo de (I) se pode obter uma oração expandida como em (II) e viceversa.

${ }^{4}$ Se for usado um adjetivo com concordância de gênero e número, a questão fica mais clara:

(I) O que Maria é é escandalosa.

(II) O que Maria é é escandaloso.

Em (I) há uma leitura especificacional, que significa que Maria é escandalosa. Em (II) há uma leitura predicacional, que significa que a propriedade que Maria tem, por exemplo, ser fofoqueira, é escandaloso.

${ }^{5}$ Ver a discussão de Zubizarreta (1998) sobre a estrutura informacional da sentença.

${ }^{6}$ Di Tullio (1999) discute três tipos de sentenças:
} 
A: O João está chorando?

B: Não, É O PEDRO que está chorando.

(6) A: O que está acontecendo aqui?

B: Nada. É o Pedro que está chorando.

No exemplo em (5) há uma construção de clivagem porque além da estrutura sintática específica, o elemento em destaque equivale ao $x$, ou seja, fixa o valor da variável (embora neste caso, o que aconteça é uma correção do valor atribuído à variável):

a. Existe um $x$ tal que $x$ está chorando.

b. $x=\mathrm{o}$ Pedro.

Já no exemplo em (6), o constituinte que aparece linearmente no lugar de $X$, na fórmula $\mathrm{SER} \mathrm{X} \mathrm{CP}$, não pode fixar o valor da variável, porque a leitura de (6) seria (8) abaixo:

(8) a. Existe um $x$ tal que $x$ está acontecendo.

b. $x=\mathrm{O}$ Pedro está chorando.

O exemplo em (8) mostra que o sujeito é parte do constituinte $x$ maior que satisfaz o valor da variável e, portanto, não gera leitura semântica específica de clivagem.

Sintetizando, a definição que assumo restringe a clivagem àquelas construções que possuem uma estrutura sintática características (são construções perifrásticas) e uma leitura semântica específica (são construções com leitura especificacional). Se um dos dois critérios não for atendido, não considero como clivagem.

\section{UMA PROBLEMATIZAÇÃO}

Nos estudos sobre a clivagem em inglês (cf. PRINCE, 1978; SORNICOLA, 1988; LAMBRECHT, 2001), construções como (9), seja com "who" (quem) ou "that" (que), são consideradas como it-clefts (clivadas)". Modesto (2001) questiona essa classificação dado que a alternância "who"/ "that" não altera a gramaticalidade em (9) mas o faz em (10) (grifos meus):

(I) Es Pedro el que está llorando.

(II) Es Pedro que está llorando.

(III) Es que Pedro está llorando.

e mostra que, embora linearmente sejam semelhantes, estrutural e semanticamente são diferentes. Os exemplos em (5) e (6) são adaptações e sínteses das diferenças discutidas em Di Tullio (1999).

${ }^{7}$ Lembrar que, na literatura sobre o português, como se verá com detalhes a seguir, essas construções são analisadas como tendo estruturas diferentes. 
(9) a. It was Jonh that wore a white suit at the dance last night.

b. It was Jonh who wore a white suit at the dance last night.

(MODESTO, 2001, p. 19)

(10) a. *It was beautiful that wore a white suit last night.

b. It was beautiful who wore a white suit last night.

(MODESTO, 2001, p. 19)

Para Modesto (2001), se tal distinção não fosse relevante, as quatro orações deveriam ser gramaticais e o par em (10) não deveria ser sensível à troca de "who" por "that". No entanto, a crítica de Modesto (2001) perde força quando o autor comenta que "beautiful" não é um elemento que pode fixar o valor da variável e, portanto, não pode ser uma construção de clivagem. É possível transcrever (9) em uma estrutura como a ilustrada em (4) acima, mas (10) é impossível de ser transcrita dessa maneira, como mostra o contraste entre (11) e (12) a seguir:

(11) a. There is a $x$, such that $x$ wore a white suit at the dance last night.

b. $x=$ Jonh.

(12) a. There is a $x$, such that $x$ wore a white suit at the dance last night.

b. $* x=$ Beautiful.

Por um lado, (11) mostra que "Jonh" satisfaz o valor de $x$, que equivale ao sujeito da sentença. Por outro lado, (12) mostra que "beautiful" não pode satisfazer esse requerimento. Desta forma, é possível concluir que a diferença entre (9) e (10) não se deve ao fato de que "who" e "that" tenham status diferente nestes contextos, mas que são construções diferentes: (9) uma construção de clivagem e (10) uma construção copulativa comum ${ }^{8}$.

Nesta seção, quis mostrar que o argumento que se levantou para considerar a diferença entre "que"/ "quem" por Modesto (2001), por exemplo, está baseado em tipos de orações diferentes (um exemplo de oração copulativa comum contrastando com um exemplo de construção de clivagem) e, portanto, essa distinção entre "who"/ "that" não se aplica às construções de clivagem que estão em discussão neste trabalho.

\footnotetext{
${ }^{8}$ Essa questão fica evidente quando outras construções de focalização são usadas como paráfrase. O exemplo (9) pode ser parafraseada como (I), porém o exemplo (10) não pode ser parafraseado como (II), que tem estrutura semelhante a (I):

(I) JONH wore a white suit at the dance last night.

(II) *BEAUTIFUL wore a white suit at the dance last night.

O contraste entre os exemplos reforça a discussão sobre a contração e a extensão perifrástica feita por Moreno Cabrera (1999) na definição da clivagem, como pontuado acima. Uma vez que uma construção de clivagem deve ter o mesmo valor de verdade que sua contraparte não clivada, percebe-se que as duas orações efetivamente são diferentes.
} 


\section{REVENDO ALGUMAS ANÁLISES}

Esta seção apresenta, em ordem cronológica, algumas análises feitas de que tenho conhecimento para a estrutura das CL e PCE no português. Como meu objetivo é propor uma análise unificada para as duas construções, de maneira sintetizada, a parte relevante dos trabalhos para a discussão que estou propondo (se CL e PCE têm a mesma estrutura ou não). Os trabalhos listados são, evidentemente, mais complexos que isso, mas por questão de espaço, preciso me deter na parte relevante para este trabalho.

\subsection{Casteleiro (1979)}

O trabalho de Casteleiro (1979) discute a sintaxe e a semântica das construções com "é que", especialmente o que é denominada de clivada invertida. O que vale destacar desse trabalho com relação as duas construções em discussão é que as CL e PCE são analisadas como tendo a mesma estrutura. À nota (1), Casteleiro (1979, p. 97) apresenta os tipos de clivagem e sua estrutura, apresenta como clivada o seguinte exemplo:

(13) Foi bolos (o) que o Rui comeu ontem.

e diz que, nesse caso, há uma oração relativa. É possível concluir, portanto, que para o autor ambas as construções são clivadas e têm como constituinte uma oração relativa.

\subsection{Kato et alii (1996)}

Kato et alii (1996, p. 329) consideram as orações em (1) e (2) ambas como clivadas, propondo três formas para a estrutura básica da clivagem:
a. Expl. ser
[XP [a pessoa
$[\mathrm{cP} O \mathrm{Op}$
[que...]]]]
b. Expl. Foi
[você
[a pessoa
[CP Op
[que eu vi]]]]

$\begin{array}{lllll}\text { a. ser } & {[\mathrm{XP}} & {[\mathrm{NP}} & {[\text { СР Q }} & [(\text { que }) . . .]]]] \\ \text { b. Foi } & {[\text { você }} & {[\mathrm{NP}} & {[\text { ср quem }} & [\text { eu vi] }]]]\end{array}$

$\begin{array}{lllll}\text { a. ser } & {[\mathrm{XP}} & {[\mathrm{NP}} & {[\mathrm{CP} \text { Op }} & {[\text { que...]]]] }} \\ \text { b. Foi } & {[\text { você }} & {[\mathrm{NP}} & {[\mathrm{CP} \mathrm{Op}} & [\text { que eu vi }]]]\end{array}$

A análise das autoras propõe uma estrutura unificada para ambas as construções CL e PCE, no sentido de que os três tipos se originam a partir de uma estrutura como "SER X RELATIVA" diferenciando-as apenas pelo preenchimento de uma ou outra posição dentro do sistema CP: em (14), tem-se o núcleo da relativa preenchido por um nome genérico, como "coisa", "pessoa" ou 
"dia", o especificador do CP vazio (ocupado por um operador nulo) e o núcleo do $\mathrm{CP}$ preenchido; em (15), tem-se o núcleo da relativa vazio, o operador realizado no especificador do CP e o núcleo do CP preenchido opcionalmente; em (16), tem-se o núcleo da relativa vazio, o especificador do $\mathrm{CP}$ vazio (ocupado por um operador nulo) e o núcleo do $\mathrm{CP}$ preenchido.

\subsection{Longhin (1999)}

O trabalho de Longhin (1999) faz um estudo das construções de clivagem na diacronia do português. Como o trabalho de Longhin (1999) é de cunho funcionalista, pouco vai nos servir para a discussão apresentada aqui. Contudo, na introdução de seu trabalho, a autora mostra como concebe a estrutura das construções de clivagem:

(17) a. É o mundo todo que está assim. (Clivada propriamente dita)

b. A genética é que produziu uma série de transformações. (Construção É QUE)

c. Por isso que os outros desconfiam mais dele. (Construção Que)

d. Agora, eu encontro é uma certa ataraxia por parte da classe política no sindicalismo moderno. (Construção Ser Foco)

e. Quem faz realmente esta poesia sintática e ideogrâmica são os senhores. (Pseudo-clivada)

(LONGHIN, 1999, p. 13-14)

A autora continua: "É possível que o elemento-Q das clivadas codifique o traço [+hum] do referente focal nas CLIVs, É QUEs e PCs [...]. A seguir, ofereço dois exemplos em que há codificação do traço [+hum]" (LONGHIN, 1999, p. 15). Os exemplos da autora são apresentados de forma adaptada a seguir:

(18) a. Foi ele quem primeiro falou em Antonio Gramsci.

b. Oswald foi que, pela primeira vez, pensou de maneira não sistemática.

(LONGHIN, 1999, p. 15)

A autora conclui:

Sentenças como essas assinaladas em (10) e (11) são consideradas, neste trabalho, como exemplos de CLIV e É QUE, respectivamente. A classificação dessas sentenças é motivo de divergência entre lingüistas. Alguns argumentam que elas devem ser discutidas como PC com ordem invertida, enquanto outros afirmam que não devem ser discutidas como clivagem, mas como outro tipo de focalização diferente que envolvem uma small clause. Concordo com os primeiros, por acreditar que ao menos em uma de suas leituras elas sejam clivadas verdadeiras, mas o rótulo é infeliz. Ainda que formalmente essas construções se assemelhem às $\mathrm{PCs}$, sintática e discursivamente elas se aproximam mais às CLIVs e É QUEs, o que justifica o tratamento que dedico a elas. (LONGHIN, 1999, p. 15) 
Ou seja, mesmo que Longhin (1999) não ofereça um tratamento formal gerativista a essas construções, fica claro seu posicionamento de que ambas as construções devem ser tratadas como clivadas.

\subsection{Modesto (2001)}

Modesto (2001) apresenta estruturas diferentes paras os dois tipos de construções: a CL apresenta estrutura específica enquanto a PCE é derivada da extraposição da oração relativa livre que ocupa a posição de predicado da small clause. Ou seja, Modesto (2001) distingue entre orações clivadas e orações pseudo-clivadas. $\mathrm{O}$ autor assume que as construções clivadas são constituídas por duas orações (uma nucleada pela cópula focalizadora, que subordina a outra oração nucleada pelo verbo da predicação principal) e que as pseudo-clivadas são constituídas por uma oração copulativa simples na qual o foco é predicado e a oração relativa livre é o sujeito.

Para a derivação da CL, Modesto (2001) propõe que o foco se move da sua posição dentro do IP, onde é saturado tematicamente, e checa os traços de foco no $\mathrm{CP}$ subordinado ao verbo copulativo, realizando um movimento A-Barra. Para a derivação da PCE, a partir da estrutura e derivação da pseudo-clivada, a relativa livre se move da posição de predicado da small clause para specTP para satisfazer o movimento A-Barra ${ }^{9}$ e, em seguida, é extraposta para a direita em adjunção a TP.

Como o próprio Modesto (2001) comenta, no caso da CL, quem faz o movimento A-Barra é o foco e, no caso da PCE (como em todas as pseudoclivadas), é a relativa livre. Esse movimento da relativa proposto por Modesto (2001) está relacionado com a satisfação de regras fonológicas, seguindo Zubizarreta (1998).

Embora haja o movimento da relativa para uma posição A-Barra (SpecTP) para satisfazer regras fonológicas (que operam no $\mathrm{PE}$ mas não no $\mathrm{PB}^{10}$ ), não há motivação para a extraposição ${ }^{11}$ : quando a relativa ocupa a posição de SpecTP, fazendo o movimento A-Barra, o foco já está em uma posição mais encaixada e pode receber o acento nuclear responsável pela interpretação focal. Modesto (2001, p. 62) diz que:

\footnotetext{
${ }^{9}$ Para Modesto (2001), SpecTP é uma posição A-Barra. SpecAgrP é que se configura como uma posição A.

${ }^{10}$ Trabalhos mais recentes, como Fernandes-Svartman (2007), que relaciona prosódia e ordem de palavras, mostram que o português do Brasil não apresenta o movimento prosodicamente motivado para satisfação do foco, proposto por Zubizarreta (1998) para algumas línguas românicas.

${ }^{11}$ E aqui retomo um dos pilares básicos do Programa Minimalista (Chomsky, 1995 e desenvolvimentos posteriores): os movimentos só devem ser postulados com motivação e são operações de último recurso.
} 
Pode-se imaginar porque não analisar a relativa livre na sua posição de geração, adiando o movimento para LF. Por um lado, o movimento em (19a) [Quem quer casar é a Susanita], na sintaxe visível, indica que o movimento em (19b) [É a Susanita quem quer casar] também deve acontecer antes de spell-out, admitindo que o princípio minimalista da procrastinação seja efetivo (cf. Chomsky (1992)). Por outro lado, veremos no capítulo III que esse movimento é prosodicamente motivado e, por essa razão, tem necessariamente de acontecer antes da entrada para PF (antes de spell-out).

Pode-se concluir, portanto, que tal extraposição é realizada com o único objetivo de dar conta da ordem linear da oração, o que torna a análise de Modesto (2001) para as PCE inadequada dentro do programa minimalista.

\subsection{Brito e Duarte (2003)}

Todas as construções de clivagem são analisadas por Brito e Duarte (2003) como possuindo uma mesma estrutura: um verbo copulativo selecionando como complemento uma oração pequena - OPeq (small slause), como mostra (19):

(19) $\operatorname{ser}[\mathrm{oPeq}$

[a] o queijo] (BRITO e DUARTE, 2003, p. 687)

O símbolo $\alpha$ corresponde a um constituinte oracional que contém uma posição vazia vinculada a um operador cujo valor é fixado pelo constituinte clivado. O que diferencia a CL da PCE é o fato de o constituinte oracional ser uma pseudo-relativa (com que invariável) na primeira e uma relativa na segunda, como ilustram (20) e (21):

$\left[\right.$ SFlex $\operatorname{ser}\left[\right.$ oPeq $\quad\left[\right.$ sComp$_{2}\left\{[\text { o que }]_{\mathrm{i}} / O P_{\mathrm{i}}\right.$ que $\}$ o corvo comeu $\left.\left.\left.[\mathrm{v}]_{\mathrm{i}}\right][\mathrm{sN} \text { o queijo }]_{\mathrm{i}}\right]\right]$

(BRITO e DUARTE, 2003, p. 688)

(21) a. [SFlex

foi $\left[\right.$ oPeq $[\mathrm{sN} \text { o bolo }]_{\mathrm{i}}\left[\mathrm{OPeq}\left[\mathrm{sComp}[\mathrm{o} \text { que }]_{\mathrm{j}} \text { o João comeu }[\mathrm{v}]_{\mathrm{j}}[\mathrm{v}]_{\mathrm{i}}\right]\right]_{(\mathrm{i}=\mathrm{j})}$

b. $[$ SFlex

foi [oPeq [sN o bolo $]_{\mathrm{i}}$ [oPeq $_{\text {[sComp }} O p_{\mathrm{j}}$ que o João comeu $\left.\left.[\mathrm{v}]_{\mathrm{j}}[\mathrm{v}]_{\mathrm{i}}\right]\right]_{(\mathrm{i}=\mathrm{j})}$

(BRITO e DUARTE, 2003, p. 689)

A partir da estrutura básica em (20), se pode observar que, em (21), o foco é adjungido à small clause. No caso da PCE em (21a), o pronome relativo é vinculado ao foco e o núcleo do sintagma complementizador fica vazio. No caso da CL em (21b), o operador nulo está vinculado ao foco e a posição de núcleo do complementizador está preenchida.

Kato et alii (1996) e Brito e Duarte (2003) apresentam diferenças: a) Brito e Duarte (2003) assumem sempre uma relativa livre (mesmo em (21b), com apenas o núcleo "que" realizado, o que nunca acontece em verdadeiras orações relativas livres) enquanto Kato et alii (1996) levantam a possibilidade de a relativa ter cabeça, sendo o núcleo preenchido por um nome genérico; b) as relativas com nome genérico podem ser clivagem para Kato et alii (1996) mas 
não para Brito e Duarte (2003); c) o foco é adjungido à small clause na análise de Brito e Duarte (2003) mas sua origem, se é gerado na base ou movido, não fica explicitada em Kato et alii (1996).

As análises de Brito e Duarte (2003) e Kato et alii (1996) apresentam a mesma estrutura com preenchimento diferenciado em cada uma (se o $\mathrm{C}^{\mathrm{o}}$ é preenchido, tem-se uma CL; se o SpecCP é preenchido, tem-se uma PCE). No entanto, discordo da existência de uma oração relativa nesses casos e argumentarei abaixo que as construções de clivagem desse tipo não podem ser constituídas por uma oração relativa.

\subsection{Mioto e Negrão (2007)}

Mioto e Negrão (2007) fazem uma discussão sobre relativas com antecedente, relativas livres e clivagem para mostrar que o $\mathrm{CP}$ das clivadas não contém uma relativa, mas sim uma oração integrante do tipo that-clause. Com respeito ao que toca às construções discutidas aqui, os autores assumem que: a) há diferença entre clivadas e pseudo-clivadas, seguindo o espírito de Modesto (2001); b) CL e PCE têm estruturas diferentes. Mioto e Negrão (2007) assumem que a PCE possui uma relativa livre enquanto que a CL não, sendo este o aspecto central de sua argumentação.

\subsection{Kato e Ribeiro (2009)}

Kato e Ribeiro (2009) fazem uma discussão sobre a história da clivagem no português dentro do quadro gerativista assumindo a hipótese de que construções cuja cópula é o primeiro elemento só aparecem após o período V2. As autoras discutem estratégias diversas de focalização e clivagem e, com relação às construções em debate aqui, assume que são construções diferentes.

Por um lado, Kato e Ribeiro (2009) analisam a CL de maneira similar ao modelo de Modesto (2001) discutido acima. As possíveis diferenças são decorrentes de atualizações do modelo teórico. Por outro lado, embora Kato e Ribeiro (2009) assumam que as PCE sejam construções copulativas, com uma oração relativa livre na posição de predicado, a análise das autoras difere da de Modesto (2001) porque assumem que o foco realiza o movimento da posição de especificador da small clause para a posição de especificador de FocP da periferia do VP no espírito de (BELLETTI, 2004). Como a cópula se move de $\mathrm{V}^{\mathrm{o}}$ para $\mathrm{T}^{\mathrm{o}}$, a análise das autoras não precisa recorrer à extrapolação da relativa livre, que pode permanecer in-situ.

Essa análise, efetivamente, é mais interessante que a de Modesto (2001) em termos minimalistas mesmo assumindo que as duas construções são diferentes e não capturando a intuição da tradição anglo-saxônica de que as duas orações são clivadas. 


\subsection{Síntese}

Das análises apresentadas até aqui, é possível agrupar os trabalhos em pelo menos dois grupos: a) aqueles que consideram as duas orações como tendo a mesma estrutura (CASTELEIRO, 1979; KATO et alii, 1996; LONGHIN, 1999; BRITO e DUARTE, 2003); b) aqueles que consideram as duas orações com estruturas diferentes (MODESTO, 2001; MIOTO e NEGRÃO, 2007; KATO e RIBEIRO, 2009). Embora o primeiro grupo capture, em alguma medida, a intuição de que ambas as construções são do mesmo tipo, mantêm, por outro lado, a proposta tradicional de que o elemento $\mathrm{WH}$ dessas construções é um pronome relativo. Como argumentarei a seguir, essas construções dão evidências de que o elemento WH não se caracteriza como um pronome relativo mas sim como uma conjunção integrante do tipo "that" do inglês.

\section{SEM ORAÇÕES RELATIVAS}

Nesta seção, meu objetivo é uma breve discussão para mostrar que os dois tipos de construção de clivagem em discussão não apresentam uma oração relativa, para, mais abaixo, argumentar que possuem uma oração integrante do tipo that-clause.

No português são atestadas construções de clivagem sem cópula:
A: Quem fez o bolo?
B: Eu que fiz.

No caso em (22), a análise mais comum é que essas construções são derivadas da contraparte com a cópula, ou seja, da clivada, com o posterior apagamento da cópula e que a partícula "que" é uma conjunção integrante, ou seja, o núcleo $\mathrm{C}^{\text {o }}$.

Porém, no PB abundam as seguintes construções (registradas por mim em conversas espontâneas na internet) (grifos meus):

a. A: vc quer ou nao ser meu amigo?

B: vc quem sabe...amigo pra mim me traz paz, nao chateação ${ }^{12}$.

b. A: entao to vendo quando vao me mandar os bilhetes pra barcelona

B: ah... ainda nao decidiram isso?

A: pois e eles quem vao me dar o voo

c. Ok CF, vc quem sabe.

d. Querido, obrigada. mas sem vcs nada disso teria sido possível. eu quem agradeço.

e. Tô dentro. Onde eu assino para entrar? eu ando de bus, fiz minha faculdade porque eu quem paguei e nunca dependi de governo fdp nenhum.

12 Como se vê claramente, essa oração não é interrogativa indireta. Não há uma pergunta. Há uma asserção e essa oração equivale a "É você que(m) sabe se vamos ser amigos ou não". 
Se as orações WH dos exemplos em (23) forem analisadas como orações relativas, os dados deveriam ser agramaticais pela teoria temática. "Você quem sabe" não é uma oração completa: o verbo "sabe" seleciona tematicamente o pronome relativo "quem" formando a oração relativa "quem sabe", que seria um modificador de "você", mas "você quem sabe", por outro lado, fica sem receber papel temático de algum predicado, se caracterizando como um constituinte sem predicação. Observe-se que uma ordem equivalente com a leitura efetivamente de modificação não focal é agramatical:

a. O menino que chegou. (leitura focal)

b. O menino quem chegou. (leitura focal) $)^{13}$

c. ${ }^{*}$ O menino que chegou. (leitura de modificação) ${ }^{14}$

d. *O menino quem chegou. (leitura de modificação)

e. O menino que chegou é filho da Maria. (leitura de modificação)

f. *O menino quem chegou é filho da Maria. (leitura de modificação)

Observe-se ainda que a forma "quem" não pode ser empregada na oração relativa restritiva dada a agramaticalidade de (24f), o que contrasta com a leitura focal de (24b), em que "quem" é possível. Os contrastes entre as formas "que" e "quem" nos exemplos em (24) sugerem que não se tratam das mesmas categorias em todos os pares de oração: "que" e "quem" em (24a) e (24b) não pertencem à mesma categoria que "que" e "quem" em (24e) e (24f); por isso, teriam comportamentos diferentes.

Nesta esteira, o segundo argumento vem do fato de que as orações relativas livres são equivalentes a um sintagma nominal ${ }^{15}$. À primeira vista, a análise das

13 O trabalho de Medeiros Júnior (2017) discute, retomando as propostas de Mioto (1996, 2001), construções como (24a) propondo que não há apagamento da cópula mas que "que" seja um marcador focal de uma oração simples ocupando o núcleo Foc ${ }^{\circ}$. Vale a pena destacar, no entanto, que parece que a análise de "quem" como marcador focal simples no mesmo sentido que "que", neste caso, é trazida ao cenário pela primeira vez por mim em Pinto (2008).

${ }^{14}$ Um dos pareceristas anônimos observa que essa oração não deveria ser agramatical considerando o par pergunta-resposta:

A: Quem você está procurando?

$\mathrm{B}$ : O menino que chegou.

Estamos de acordo com o parecerista; mas, não é este caso que estou discutindo. A argumentação do parecerista 1 parece ser análoga a contestar a teoria dos papeis temáticos porque há objetos nulos ou verbos de ação, por exemplo. Em um contexto neutro, "out of the blue", a oração (24c) é tão agramatical como "Eu comi" seria. A gramaticalidade de (24c) depende de um contexto de apagamento de pressuposição "e menino que chegou", no qual a pressuposição apagada conteria o predicado que selecionaria o DP como complemento.

${ }^{15} \mathrm{Na}$ nomenclatura gerativista, as relativas livres teriam a mesma distribuição que os DPs e não funcionariam, portanto, como modificadores do nome, de maneira oposta ao que acontece com as relativas com antecedente:

(I) Não conheço quem fale japonês.

(II) Não conheço falante de japonês. 
pseudo-clivadas como orações copulativas parece ser coerente dada a possibilidade das orações copulativas equativas a seguir em (25):
a. João é o professor.
b. O professor é João
c. É João o professor.

Contudo, a análise não se sustenta para os casos em (22) e (23) uma vez que orações copulativas equativas sem a cópula são agramaticais ${ }^{16}$ :
a. *João professor.
b. *Professor João. ${ }^{17}$

Se orações copulativas equativas sem cópula são agramaticais, a previsão é que pseudo-clivadas sejam também agramaticais sem a cópula ${ }^{18}$. Essa previsão se confirma para a pseudo-clivada básica porém é falsa para a $P C E$ :

a. *Quem comeu o bolo Pedro.

b. Pedro quem comeu o bolo.

O contraste na gramaticalidade em (27) sugere que (27b) não pode ser uma oração copulativa com posterior apagamento da cópula. ${ }^{19}$

(III) Quem chegar por último é a mulher do padre.

(IV) O João é a mulher do padre.

${ }^{16}$ Hernanz e Brucart (1987) pontuam que em russo, orações copulativas no tempo presente não precisam da cópula. Observe-se, portanto, que o licenciamento é dado pelo presente, tempo não marcado. Nos demais casos, a cópula é obrigatória.

${ }^{17}$ Exclua-se a leitura apositiva de João.

${ }^{18}$ Essa previsão vem do fato de que pseudo-clivadas (diferentemente das clivadas) são analisadas como orações copulativas equativas, conforme bem discute Modesto (2001), Resenes $(2009,2014)$ entre outros. Nesse sentido, as pseudo-clivadas estão sujeitas às mesmas restrições que orações copulativas equativas normais uma vez que a oração relativa livre da pseudo-clivada é um DP.

${ }^{19}$ Hernanz e Brucart (1987) e Brucart (1999) discutem a existência ou não de categorias vazias e concluem que é preciso assumir a existência de elementos que não são pronunciados. No entanto, argumentam que a proposição de categorias vazias deve ser um último recurso utilizado somente quando não é possível manter a análise sem a categoria apagada. Brucart (1999), apesar de discutir o espanhol, mostra claramente que as categorias vazias obedecem a restrições de recuperabilidade para que possam ser licenciadas em contextos de elipse. A elipse verbal parece ser possível apenas em contextos de o significado do verbo apagado pode ser recuperado pelo contexto anterior. Sendo a cópula um elemento funcional vazio de significado, portanto, impossível de ter seu significado recuperado pelo contexto, é possível descartar a análise do seu apagamento porque não atenderia às condições sintáticas e semânticas de recuperabilidade. Os argumentos fonológicos trazidos por Mioto (1996) também descartam o apagamento da cópula no nível fônico uma vez que mesmo em sua forma monossilábica "é", a cópula é tônica e elementos tônicos não são susceptíveis a apagamento. 
Mioto e Negrão (2007) fazem um estudo no qual relacionam sintaxe com prosódia para mostrar que as clivadas não possuem uma oração relativa e destacam que uma oração como (28) pode ser uma possível resposta às perguntas em (29):

(28) Foi o aluno que foi reprovado.

(29) a. Quem foi que foi reprovado?

b. Qual foi o aluno que pediu revisão de prova?

(MIOTO e NEGRÃO, 2007, p. 174)

Neste ponto, é trazida ao debate a discussão sobre a fixação do valor da variável. A oração em (28) só pode ser uma construção de clivagem como resposta à pergunta em (29a). Como resposta à oração em (29b), (28) é uma oração relativa restritiva.

Para mostrar que relativas restritivas e clivadas são diferentes e que as clivadas não possuem uma relativa, Mioto e Negrão (2007) recorrem à análise prosódica das respostas produzidas por falantes do PB: como resposta à (29a), o pico acentual de (28) está localizado na silaba tônica do foco -lu-; como resposta à (29b), o pico acentual está na sílaba tônica do constituinte mais encaixado -va-. Em outras palavras, se a estrutura fosse idêntica, a prosódia deveria ser idêntica também.

Em suma, se as clivadas possuíssem uma oração relativa, seria esperado que o comportamento do $\mathrm{CP}$ das clivadas fosse igual ao do $\mathrm{CP}$ das orações relativas, o que não é comprovado pelos dados empíricos. Essa conclusão óbvia vem à baila para antecipar que, conforme já sinalizei brevemente acima e irei desenvolver a seguir, "quem", "onde", "o que" etc. das PCE também não seriam pronomes relativos e não introduziriam, no caso da PCE, oração relativa.

\section{UMA PROPOSTA UNIFICADA}

\subsection{Fundamentação teórica: o Critério-Wh, a concordância e a cartografia sintática}

Rizzi (1991) estabelece um Critério-Wh, que será o responsável pela boa formação de orações interrogativas e quantificadas. Com base nos dados empíricos sobre as interrogativas do como em (30), Critério-Wh é estabelecido como em (31).

(30) a. * What Mary has said?

b. What has Mary said? (RIZZI, 1991, p. 1)

(31) Critério-Wh

A. Um operador Wh deve estar numa configuração Spec-Head com um $X_{[+w h]}^{\mathbf{o}}$.

B. Um $\mathrm{X}_{[+w h]}^{\mathbf{o}}$ deve estar numa configuração Spec-Head com um operador Wh. 
(traduzido de RIZZI, 1991, p. 2)

O exemplo (30) mostra que o sujeito não pode intervir entre o interrogativo e o verbo, o que indica que o interrogativo e o elemento verbal devem estar numa relação especificador-núcleo (Spec-Head) como proposto em $(31)^{20}$.

Rizzi (1991) também considera algumas assimetrias entre interrogativas principais e subordinadas do francês com relação à aplicação do Critério-Wh e propõe dois tipos de concordância: estática e dinâmica ${ }^{21}$. Na concordância estática núcleo e especificador apresentam um dado traço. Na concordância dinâmica o especificador é capaz de dotar o seu núcleo com os traços em questão. A concordância dinâmica só pode acontecer se as propriedades de seleção forem mantidas em toda a derivação, de acordo com o Princípio da Projeção.

Por exemplo, se um $\mathrm{V}^{\mathrm{o}}$ seleciona um $\mathrm{CP}_{[-w h]}$, este $\mathrm{CP}$ não pode ser dotado dos traços [+wh] por concordância dinâmica, porque fere, assim, o Princípio da Projeção. Trazendo a questão para uma visão minimalista, de que todos os elementos já estão com todos os traços na numeração, se um $\mathrm{CP}_{[+w h]}$ na numeração não pode ser alterado para $\mathrm{CP}_{[+ \text {wh] }}$ no decorrer da derivação e o operador $_{[+w h]}$ que ocupará $\mathrm{SpecCP}_{[-\mathrm{wh}]}$ não poderá ter os traços checados contra o $\mathrm{C}_{[-w h]}^{\mathrm{o}}$. Assim, a derivação não convergirá.

A estrutura sintática possui três níveis: VP (nível de seleção lexical); IP (nível de flexão, com licenciamento de Caso e concordância) e CP (nível complementizador, exibindo tópicos e operadores). Rizzi (1997) afirma que, do mesmo modo que foi estabelecida a cisão de VP e do IP por Larson (1988) e Pollock (1989), havia indícios de que o CP também apresenta uma estrutura maior que uma única projeção X-Barra. Assim, Rizzi (1997) propõe a seguinte estrutura para o CP:

$$
\left[\text { ForceP } \quad\left[\text { TopP }^{*} \quad\left[\text { FocP } \quad[\text { TopP* } \quad[\text { FinP } \quad[\text { IIP... }]]]^{3}\right]\right]^{22}\right.
$$

Com essa estrutura, Rizzi (1997) também propõe um Critério-Foc remanescente do Critério-Wh. Os exemplos abaixo de Zubizarreta (1999, p. 42404241) ilustram o caso:

${ }^{20}$ É preciso lembrar aqui que, na análise de Rizzi (1991) há movimento de ambos os elementos, operador e verbo. Os dados em (30) levam a Rizzi (1991) a classificar línguas como o inglês como V2 residual, nas quais o verbo se move em contextos específicos para o núcleo $\mathrm{C}^{\mathrm{o}}$, movimento que ocorre de maneira generalizada nas línguas V2 como o alemão. A relação Spec-Head, portanto, acontece no CP.

${ }^{21} \mathrm{O}$ francês altera a forma do pronome relativo a depender da função sintática. Se é sujeito, a forma é "quil". Se é qualquer outra função, a forma é "que":

(I) Le garçon qui est arrivé...

(II) La Maison que Marie a achetée...

22 A proposta inicial de Rizzi (1997), especialmente os campos de FocP e TopP, foi refinada por trabalhos posteriores como Benincà (2006) Polletto e Benincà (2004). Como o refinamento não é crucial para a minha discussão, remito o leitor aos trabalhos indicados. 
(33) a. MANZANAS dijo Maria que compró Pedro.

b. MANZANAS me aseguran que dijo Maria que compró Pedro.

c. Me aseguran que MANZANAS dijo María que compró Pedro.

d. Me aseguran que María dijo que MANZANAS compró Pedro.

(34) a. *El DIARIO Pedro compró.

b. *El DIARIO Pedro cree que compramos.

c. El DIARIO compró Pedro.

Se o foco é alçado para a oração mais alta, como em (33a) e (33b), por onde ele passar, desencadeará a inversão VS, promovendo o movimento I-to-C para satisfazer o Critério-Foc. Se o foco permanece na oração subordinada, como em (33d), apenas nessa oração será necessário o movimento I-to-C para satisfazer o Critério-Foc. Como mostra (34), se este Critério não é obedecido, o resultado é uma oração agramatical, como em (34a) e (34b), onde o foco não está numa relação Spec-Head com o verbo. Como o PB não apresenta mais inversão V-S, em lugar do movimento do verbo para o CP para satisfazer o Critério-WH/Foc, é inserida uma partícula no núcleo focal afim de satisfação desse critério ${ }^{23}$.

\subsection{Uma análise formal alternativa}

Seguindo uma proposta minimalista, quanto menos operações de movimento forem realizadas, mais econômica será a derivação e, portanto, melhor que uma operação que requer mais movimentos. Movimento sintático é entendido como último recurso e deve ser motivado por questões de checagem. Como já comentado, FocP e TopP devem obedecer aos mesmos critérios de checagem que o Critério-Wh e, em qualquer oração clivada ou pseudo-clivada, o foco deve se mover para checar seus traços em FocP. Então, em uma oração como (35),

Foi você quem comeu o queijo.

o que estaria motivando o movimento da relativa livre, segundo a análise de Modesto (2001) para ser extraposta? Na análise de Modesto (2001), a única motivação é a ordem dos constituintes.

Uma tentativa seria dizer que o elemento "quem" da relativa deve ser deslocado para ForceP, lugar de pouso dos pronomes relativos conforme Rizzi (1997), e a cópula está subcategorizando o CP como ilustrado em (36):

[vP Ser [XP você [ForceP quem comeu o queijo...

Essa análise seria adequada se fosse considerada a estrutura proposta por Kato et alii (1996), na qual a clivagem deriva de uma relativa, com apagamento

${ }^{23}$ Lopes Rossi (1993), 1996) mostra claramente que à medida que a inversão V-S diminui em interrogativas há um algumento de interrogativas clivadas. 
do núcleo. No entanto, como o CP de Rizzi (1997) em (34) mostra, o foco deve estar numa posição inferior à ForceP e, no exemplo em (36), acontece o inverso, o que mostra que "quem comeu o queijo" não pode ser uma relativa livre.

Os exemplos relevantes de Kato et alii (1996), são sintetizados abaixo:

(37) a. Foi você a pessoa que eu vi.

b. Foi você [ $\varnothing$ ] quem / que eu vi.

Observa-se, contudo, que, na clivagem (no caso das pseudo-clivadas), a relativa deve ser sem antecedente (livre) e, no exemplo em (37a), a relativa tem antecedente "a pessoa", embora possa estar nulo, como em (37b) ${ }^{24}$. Considerando a análise proposta por Brito e Duarte (2003) para as relativas, pode-se considerar a oração (37a) como uma construção focal não clivada tendo em vista que uma relativa restritiva equivale a um adjetivo:

(38) a. Esses são [DP os professores [CP que se responsabilizaram pelo processo]].

b. Esses são [DP os professores [Adjp responsáveis pelo processo]].

c. São esses [DP os professores [CP que se responsabilizaram pelo processo]].

d. São esses [DP os professores [Adjp responsáveis pelo processo]].

A partir dos exemplos de (38), se nota que o DP "os professores que se responsabilizaram pelo processo" é equivalente ao DP "os professores responsáveis pelo processo", e que o DP modificado pelo adjetivo em (38b) e (38d) não constituem clivagem. Assim, a estrutura (considerando apenas a parte relevante) que proponho para os exemplos em (38) é a representada em (39), onde há uma small clause:

(39) São [sc [DP esses] [DP os professores [CP que [IP $_{i} t_{i}$ se responsabilizaram pelo processo]]]

São [sc [DP esses] [DP os professores [AdvP responsáveis pelo processo]]]

Ou seja, as construções que Kato et alii (1996) consideram como clivadas pelo fato de conterem uma relativa com núcleo preenchido com um nome genérico são analisadas aqui como uma copulativa focal não clivada já que o predicado da small clause é um DP formado por uma relativa com cabeça e não por uma relativa livre.

Voltando à derivação das construções de clivagem em questão, seguindo as propostas de Rizzi $(1991$; 1997) sobre a concordância dinâmica e que FocP deve checar traços segundo o Critério-Foc, proponho que o foco, ao se mover para SpecFocP possa desencadear algum tipo de concordância de Caso e/ou traços $\varphi$ com o núcleo $\mathrm{Foc}^{\mathrm{o}}$ numa configuração Spec-Head.

\footnotetext{
${ }^{24}$ Voltar à discussão de Mioto e Negrão (2007) e lembrar que "quem" não pode ser usado em orações adjetivas restritivas, o que, mais uma vez, é um argumento a favor de que as construções de clivagem discutidas aqui não podem ter uma oração relativa.
} 
Ribeiro (1995, p. 31) recorre a dados de línguas germânicas para mostrar que o complementizador pode apresentar traços de concordância de número e pessoa:
a. ...da
b. ...dan-k
c. ...da-me
d. ...dan
e. ...da-se
f. ...dan-ze

Jan

Jan en Pol

Nota-se, em (40), que o complementizador "dat" apresenta marcas de flexão para pessoa e número. Se o núcleo de $\mathrm{C}^{\mathrm{o}}$ de umas línguas pode apresentar marcas de flexão, constata-se que o traço está universalmente presente mesmo que não esteja realizado.

Esta possibilidade de concordância não fere o Princípio da Projeção, que regula as propriedades de seleção dos núcleos lexicais: o $\mathrm{CP}_{[+\mathrm{F}]}$ continua sendo selecionado pela cópula focalizadora e apenas terá seu núcleo dotado dos traços de Caso e $\varphi$ do foco movido para seu especificador desencadeando, assim, a concordância. Outro argumento que corrobora o não ferimento do Princípio de Projeção no caso da concordância dinâmica de $\mathrm{Foc}^{\circ}$ com SpecFocP é que, segundo Rizzi (1997), os traços $[ \pm \mathrm{F}]$ são inerentes ao núcleo $\mathrm{Foc}^{\mathrm{o}}$, diferentemente dos traços $[ \pm \mathrm{Wh}]$, que são transmitidos por outro núcleo funcional, como $\mathrm{I}^{\mathrm{o}}$; por conseguinte, um $\mathrm{CP}_{[-\mathrm{F}]}$ não pode se converter em $\mathrm{CP}_{[+\mathrm{F}]}$ por concordância dinâmica.

Dentro de uma visão minimalista, o traço $[+\mathrm{F}]$ do $\mathrm{CP}$ já vem com ele na numeração. Assim, quando o $\mathrm{XP}_{[+\mathrm{F}]}$ é movido para SpecFocP, apenas checará os traços contra $\mathrm{Foc}^{\mathrm{o}}$. A numeração pode conter o complementizador default ou o dotado de concordância (um ou o outro, nunca os dois): no caso do Foc [-conc] $_{\text {a }}$ derivação converge por default; no caso do $\mathrm{Foc}_{[+\mathrm{conc}]}^{\mathrm{o}}$ a derivação converge porque os traços do especificador são compatíveis com os traços do núcleo. Como os traços de Caso e concordância do complementizador não são interpretáveis em LF (Forma Lógica), não sendo relevantes, portanto, para a interpretação semântica, podem aparecer na numeração ou não.

No tocante à estrutura dessas orações, proponho, inicialmente, para ambos os casos, a estrutura semelhante à proposta por Modesto (2001) para as CL em que uma cópula focalizadora seleciona um $\mathrm{CP}_{[+\mathrm{F}]}$ no qual o foco vai ter os traços checados numa configuração Spec-Head como em (41) abaixo:
a. Foram $\left[\right.$ Foc $[\text { SpecFocP OS meninos }]_{i}$
b. Foi [Foc $[\text { SpecFocP ali }]_{\mathrm{i}}$
[Foc ${ }^{\circ}$ que/quem [IP $t_{i}$ chegaram] $\left.]\right]$
[Foc ${ }^{\circ}$ que/onde [IP eu nasci $\left.\left.\left.\mathrm{t}_{\mathrm{i}}\right]\right]\right]$
c. Foi [Foc [SpecFocP O livro de inglês $]_{i}$ [Foc ${ }^{\circ}$ que/o que [IP o Pedro comprou $\left.\left.t_{i}\right]\right]$
d. Foi $\quad\left[\right.$ Foc $[\text { SpecFocP Ontem }]_{i}$
[Foc ${ }^{\circ}$ que/quando [IP você foi lá $\left.t_{i}\right]$ ]

Em todos os casos em (41), há um movimento A-Barra do foco, que se move de alguma posição dentro do IP para SpecFocP do CP subordinado pela cópula focalizadora. 
Os dados em (42) a seguir sugerem um argumento contra a estrutura de (41), de que a CL e PCE são constituídas por uma that-clause e não por uma oração relativa.

a. A mesa onde que eu botei o livro é a minha.

b. Onde que eu botei o livro foi na minha mesa.

c. Na minha mesa foi onde que eu botei o livro.

d. Foi na minha mesa onde que eu botei o livro.

Parece que as construções em (42) sofrem diferentes juízos de gramaticalidade devido à escolaridade e à variação dialetal. Porém, são observadas em buscas eletrônicas. Nos quatro exemplos, o especificador "onde" aparece juntamente com o núcleo "que". Em (42a), há uma oração relativa com antecedente, em que ambos, núcleo "que" e especificador "onde", são preenchidos (o antecedente está fora do CP). O CP de (42b) e (42c) se trata, de fato, de uma oração relativa livre ${ }^{25}$.

O problema para a análise que apresentei reside no exemplo (42d). Se proponho que o foco está em SpecFocP, só há espaço apenas para um núcleo. No caso de (42d), haveria três elementos concorrendo a duas posições possíveis (uma de especificador e outra de núcleo). Há duas saídas possíveis: a) assumir que "onde que" forma um elemento gramaticalizado e ambos estão no núcleo, como acontece com "é que", em que a cópula não pode ser flexionada em número e pessoa $^{26}$ conforme foi proposto por Brito e Duarte (2003); b) Seguindo a discussão sobre recomplementação de $\mathrm{CP}$ em línguas V2 e a cartografia do $\mathrm{CP}$, como discutido em Vikner (1995), Ribeiro e Torres Morais (2012) e Pinto (2011), é possível pensar que "onde" está em Foc e "que" estaria no núcleo Fino abaixo já que o CP possui, de fato, mais de uma projeção X-Barra ${ }^{27}$.

${ }^{25}$ Embora as relativas livres sejam, na sua projeção máxima, um DP, possuem em algum nível abaixo do DP um CP tendo em vista a existência de um operador-wh.

${ }^{26}$ Observem-se os exemplos a seguir:

(I) Você é que chegou tarde.

(II) Vocês é que chegaram tarde.

(III) *Vocês são que chegaram tarde.

27 Um segundo parecerista faz, gentilmente, duas perguntas interessantes sobre a proposta que apresento. A primeira relacionada com a hipótese (a), como seriam explicados os casos de "quem que" ou "o que que" nesse contexto de gramaticalização. Uma alterativa seria descartar a hipotese de gramaticalização ou assumir como Brito e Duarte (2003) que, embora a cópula não possa ter traços de número e pessoa, pode ter de tempo. Ou seja, o primeiro elemento poderia ter algum tipo de manipulação. Como a hipótese (b) me parece mais interessante, acredito ser preferível descartar a hipótese da gramaticalização. Com relação à hipótese (b) o parecerista 2 argumenta que seria esperado encontrar um caso de topicalização entre os dois núcleos, gerando a ordem SER+FOCO+NÚCLEO1+TÓPICO+NÚCLEO2. Essa previsão é incorreta uma vez que tópicos são mais altos na estrutura que os focos. Como pontuado à nota 22, trabalhos posteriores ao de Rizzi (1997) sinalizam que a única ordem possível é Tópico-Foco mas nunca Foco-Tópico. Roberts (2004), por exemplo, propõe que em línguas V2 o primeiro constituinte esteja localizado em SpecFinP e o verbo em Fin ${ }^{\circ}$. Roberts (2004) sinaliza que, em alguns contextos, a ordem V3 não gera agramaticalidade porque o primeiro 
Ribeiro (2009) discute o Critério-Wh em construções de focalização e mostra que não há relação de Spec-Head na clivagem do português brasileiro ${ }^{28}$. Ribeiro (2009, p. 4-5) mostra que orações parentéticas não podem ocorrer entre os constituintes quando há uma relação Spec-Head e contrasta os dados do PB (43) com os do gungbe (44):

(43) a. Segundo Maria, foi João que meu irmão viu.

b. Foi João, segundo Maria, que meu irmão viu.

a. Jan, wè novi ce mo

"João FOC meu irmão viu"

b. *Jan, to Mari si ayixa me, wè novi ce mo

"João, de acordo com Maria, FOC meu irmao viu"

Em (43) do PB, é possível colocar uma oração parentética entre o foco e o núcleo, o que não caracteriza uma relação Spec-Head. Em (44) do gungbe, não é possível colocar essa oração parentética entre o foco e o núcleo, o que caracteriza uma relação Spec-Head. A conclusão de Ribeiro (2009), portanto, é que em PB o foco e $\mathrm{o}$ núcleo focalizador não estão na mesma projeção. $\mathrm{O}$ foco está posicionado em SpecFocP e o núcleo preenchido seria o núcleo mais baixo Fino .

A análise de Ribeiro (2009) ajuda a explicar por que são possíveis dados como (42d). Na representação em (45b), o foco está em SpecFocP, o núcleo com concordância é $\mathrm{Foc}^{\mathrm{o}} \mathrm{e}$ o núcleo sem concordância é $\mathrm{Fin}^{\circ}$. A representação em (45b) explica, inclusive, porque somente é possível a ordem "onde que" e não "que onde".

(45) a. Foi na minha mesa onde que eu botei o livro.

d. Foi $\left[\right.$ FocP $[\text { SpecFocP na minha mesa }]_{i}\left[\right.$ Foc $^{\circ}$ onde $\left[\right.$ Finp $\left[\right.$ Fino $^{\circ}$ que $[$ IIP eu botei o livro $\left.\left.\left.\left.\mathrm{t}_{\mathrm{i}}\right]\right]\right]\right]$

Para concluir, haveria então duas possibilidades de numeração para as construções de clivagem que estou discutindo: a) somente um núcleo focal na numeração, que seria $\mathrm{Fin}^{\circ}$, podendo ter concordância ou não; b) dois núcleos focais na numeração, que seriam $\mathrm{Foc}^{\mathrm{o}}$, com concordância, e $\mathrm{Fin}^{\mathrm{o}}$, invariável. Pode ser questionado por que a concordância acontece com núcleos diferentes. Uma saída seria apelar para a proximidade. No caso de construções com apenas um núcleo, a concordância entre SpecFocP e Fin ${ }^{\circ}$ acontece no espírito de Suñer

elemento é um marcador de cena, que é gerado na base, não intervindo, portanto, no movimento do XP para SpecFinP nem na relação desse XP com o seu vestígio/cópia deixado na posição de base. Como foco é um operador, portanto é movido para a periferia esquerda, se o tópico aparece à sua direita, gerará problema de minimalidade relativizada, interferindo na relação do operador com sua variável.

${ }^{28}$ O espírito de Ribeiro (2009) é o mesmo de Suñer (1994) para as interrogativas do espanhol, nas quais o requerimento de adjunção $\mathrm{WH}-\mathrm{V}$ não é necessariamente atestado. 
$(1994)^{29}$, através de transmissão de traços de $\mathrm{Foc}^{\circ}$ para $F i n^{\circ}$ já que não há nenhum elemento intervindo entre os núcleos (a oração parentética não se caracterizaria como elemento bloqueador). No caso de construções com dois núcleos, a concordância se daria numa relação de Spec-Head, que seria a relação mais próxima.

\section{CONSIDERAÇÕES FINAIS}

Neste trabalho, propus uma nova análise para orações que, em português, têm sido analisadas como tendo estruturas diferentes. Com extensão da proposta da concordância no $\mathrm{CP}$, pode-se dar conta da variação entre as línguas e dentro das línguas (pois, embora os exemplos sejam do PB, a estrutura pode representar outras línguas também), reduzindo assim o recurso a movimentos não motivados, como adota Modesto (2001) para a extraposição da relativa na PCE. Sugiro, portanto, que a nomenclatura seja $C L=$ clivada sem concordância; $P C E=$ clivada com concordância já que ambas são tratadas como clivadas.

Por fim, é preciso pensar na variação da tipologia da clivagem nas línguas humanas, por exemplo, como é feita a escolha por uma ou outra estratégia no caso das línguas que apresentam as duas possibilidades e como é feita a escolha de cada estratégia no caso das línguas que só possuem uma possibilidade ${ }^{30}$.

\section{REFERÊNCIAS}

BELLETTI, Adriana. Aspects of the low IP area. In: RIZZI, Luigi (org.). The structure of IP and CP: The Cartography of Syntactic Structure. v. 2. Oxford: Oxford University Press, 2004, p. 16-51.

${ }^{29}$ Suñer (1994) mostra que, embora haja inversão VS em interrogativas do espanhol, um elemento pode intervir entre o interrogativo e o verbo desde que não seja da mesma natureza:

(I) ¿Qué compró Juan?

(II) ¿Qué exactamente compró Juan?

(III) *¿Qué Juan compró?

Esses dados levam Suñer (1994) a concluir que o Critério-Wh de Rizzi (1991) não se aplica ao espanhol e que o verbo e o interrogativo não estão na mesma posição. Mais que isso: que o verbo não se move para $\mathrm{CP}$ em interrogativas do espanhol atual.

${ }^{30}$ No caso do espanhol europeu, Pinto (2013) assume a proposta de Di Tullio (1999) de que há uma pressão normativa desde o século XIX feita por Andrés Bello. Moreno Cabrera (1999) diz que o espanhol europeu não apresenta as clivadas sem concordância como (1). Pinto (2013) mostra, a partir de estudo de corpus, que essas construções como (1) são observadas em usos coloquiais do espanhol europeu atual embora não sejam atestadas em usos formais. 
BENINCÀ, Paola. A Detailed Map of the Left Periphery of Medieval Romance. In: ZANUTTINI, Raffaella et alii (orgs.). Negation, Tense and Clausal Architecture: Cross-linguistics Investigations. Washington: Georgetown University Press, 2006, p. 53-86.

BENINCÀ, Paola; POLETTO, Cecilia. Topic, Focus and V2: Defining the CP Sublayers. In: RIZZI, Luigi (org.). The Structure of CP and IP. The Cartography of Syntactic Structures. v. 2. Oxford: Oxford University Press, 2004, p. 52-75.

BRITO, Ana Maria; DUARTE, Inês. Orações relativas e construções aparentadas. In: MATEUS, Maria Helena Mira (Org.). Gramática da Língua Portuguesa. 5. ed. revista e aumentada. Lisboa: Caminho Colecção Universitária. 2003, p. 653694. Série Linguística.

BRUCART, Josep Maria. La elipsis. In.: BOSQUE, Ignacio; DEMONTE, Violeta (Orgs). Gramática descriptiva de la lengua española. v. 2. Madri: Espasa Calpe, 1999, p. 2787-2866.

CASTELEIRO, João. Sintaxe e semântica das construções enfáticas com 'é que'. Boletim de Filologia, v. XXV, 1979.

CHOMSKY, Noam. The Minimalist Program. Cambridge/Mass: MIT Press, 1995.

DI TULLIO, Ángela. Hendidas, inferenciales y presentativas. In.: DÉNIZ, Magnolia Troya; SAMPER PADILLA, José Antonio (Org.). Actas del XI Congreso Internacional de la Asociación de Lingüistica y Filología de la América Latina. Las Palmas de la Gran Canarias, 1999, p. 511-520.

FERNANDES-SVARTMAN, Flaviane. Ordem, focalização e preenchimento em português: sintaxe e prosódia. Campinas, SP, 2007. Tese (Doutorado em Lingüística), Universidade Estadual de Campinas.

HERNANZ, Maria Lluïsa; BRUCART, José Maria. La sintaxis. Principios teóricos. La oración simple. v. 1. Barcelona: Crítica, 1987.

KATO, Mary et alii. Construções-Q na gramática do português brasileiro falado: perguntas, clivadas e relativas. In: $\mathrm{KOCH}$, Ingedore. (Org.). Gramática do Português Falado: Desenvolvimentos. v. 6, Campinas: Editora da UNICAMP, 1996, p. 303-370.

KATO, Mary; RIBEIRO, Ilza. Cleft sentences from Old Portuguese to Modern Portuguese. In: DUFTER, Andreas; JACOBS, Daniel (Orgs.). Focus and background in Romance languages. Amsterdam: John Benjamins, 2009, p. 123154

LAMBRECHT, Knud. A framework for the analysis of cleft constructions. Linguistics, Berlin, n. 39, 3, 2001, p. 463-516. 
LARSON, Richard. On the double object construction, Linguistic Inquiry, Massachusetts, n. 19, 1988, p. 335- 391.

LONGHIN, Sanderléia. As construções clivadas: uma abordagem diacrônica. Campinas, SP, 1999. 195f. Dissertação de Mestrado, Universidade Estadual de Campinas.

LOPES-ROSSI, Maria Aparecida Garcia. A sintaxe diacrônica das interrogativas- $Q$ do Português. Campinas, SP, 1996, f. Tese de Doutorado, Universidade Estadual de Campinas.

(1993). Estudo diacrônico sobre as interrogativas do português do Brasil. In: ROBERTS, Ian; KATO, Mary (Orgs.). Português Brasileiro: uma viagem diacrônica. Campinas: Unicamp, 1993, p. 307-342.

MEDEIROS JÚNIOR, Paulo. Quem que vai falar? O Paulo que vai falar. Interpratando que como um núcleo de foco: sintaxe, variação e evidência diacrônica. In: PILATTI, Eloisa; SALLES, Heloísa; NAVES, Rozana (Orgs.). Novos olhares para a gramática do português brasileiro. Campinas: Pontes, 2017, p. 61-86.

MIOTO, Carlos. Sobre o Sistema CP no Português Brasileiro. Revista Letras, Curitiba. v. 56, 2001, p. 97-140.

MIOTO, Carlos. Wh é que 1 Wh que. Anais de Seminários do Gel, 1996, p. 648654.

MIOTO, Carlos; NEGRÃO, Esmeralda. As sentenças clivadas não contêm uma relativa. In: CASTILHO, Ataliba de; TORRES DE MORAIS, Maria Aparecida; LOPES, Ruth; CYRINO, Sônia. (Orgs.). Descrição, História e Aquisição do Português Brasileiro. São Paulo: FAPESP; Campinas: Pontes, 2007, p. 159-183.

MODESTO, Marcello. As construções clivadas no português do Brasil: relações entre interpretação focal, movimento sintático e prosódia. São Paulo: Humanitas, 2001.

MORENO CABRERA, Juan Carlos. Las funciones informativas: las perífrasis de relativo y otras construcciones perifrásticas. In: BOSQUE, Ignacio; DEMONTE, Violeta (Org.). Gramática descriptiva de la lengua española. v. 3. Madri: Espasa Calpe, 1999, p. 4245-4302.

PINTO, Carlos Felipe. Variación sintáctica en el español europeo - entre normativa y problemas descriptivos, Cadernos de Letras da UFF, Niterói, v. 47, 2013, p. 247-267.

Ordem de palavras, movimento do verbo e efeito $V 2$ na história do espanhol. Campinas, SP, 2011. 309f. Tese de Doutorado, Universidade Estadual de Campinas. 
POLLOCK, Jean-Yves. Verb movement, universal grammar, and the structure of IP. Linguistic Inquiry, Massachusetts, v. 20, 1989, p. 365-424.

PRINCE, Ellen. A comparison of wh-clefts and it-clefts in discourse. Language, Washington, n. 54, 1978, p. 883-906.

RESENES, Mariana. A Sintaxe das Construções Semiclivadas e Pseudoclivadas do Português Brasileiro. São Paulo, SP, 2014. 289f. Tese de Doutorado. Universidade de São Paulo.

- Sentenças Pseudo-Clivadas do Português Brasileiro. Florianópolis, SC. 2009. 143f. Dissertação de Mestrado. Universidade Federal de Santa Catarina.

RIBEIRO, Ilza. Construções de focalização: Comentários ao texto de Simone Guesser. In NAVES, Rozana Reigota; SALLES, Heloísa (orgs). Estudos formais da gramática das línguas naturais. Goiânia: Cânone Editorial. 2009, p. 109-122.

- A sintaxe da ordem no português arcaico: o efeito V2. Campinas, SP. 1995. 286f. Tese de Doutorado, Universidade Estadual de Campinas.

RIBEIRO, Ilza; TORRES MORAIS, Maria Aparecida. Doubling-que embedded constructions in old portuguese: a diachronic perspective. In: GALVES et alii (Orgs.). Parameter theory and linguistic change. Oxford: Oxford University Press, 2012, p. 97-116.

RIZZI, Luigi. The fine structure of the left periphery. In: HAEGEMAN, Liliane (Org.). Elements of grammar. Kluwer: Dordrecht, 1997, p. 281-337.

. Residual verb second and the Wh criterion. Techinical Reports in

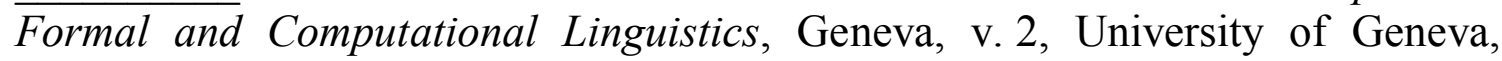
1991.

ROBERTS, Ian. The C-Systen in brythonic celtic languages, V2 and the EPP. In: RIZZI, Luigi (Org.). The Structure of CP and IP. The Cartography of Syntactic Structures. v. 2. Oxford: Oxford University Press, 2004, p. 297-328.

SORNICOLA, Rosanna. It-clefts and wh-clefts: two awkward sentence types. Journal of Linguistic, Cambridge, n. 24, 1988, p. 343-379.

SUÑER, Margarita. V-movement and the licensing of argumental wh-phrases in Spanish, Natural Language and Linguistic Theory, Cham, v. 12, 1994, p. 335372.

VIKNER, Sten. Verb movement and expletive subjects in the Germanic languages. Oxford: Oxford University Press, 1995. 
ZUBIZARRETA, Maria Luisa. Las funciones informativas: tema y foco. In.: BOSQUE, Ignacio; DEMONTE, Violeta. (Org). Gramática descriptiva de la lengua española. v. 3. Madri: Espasa Calpe, 1999, p. 4215-4244 . Prosody, focus, and word order. Cambridge, Mass: The MIT Press, 1998.

Carlos Felipe Pinto CFCPinto@gmail.com

Recebido em: 30 jan. 2018 Aceito em: 5 maio 2018 Publicado em: 1 out. 2018 